\title{
NOTAS SOBRE AS PRIMEIRAS TRADUÇÕES CIENTÍFICAS EM LÍNGUA PORTUGUESA: ASTROLOGIA E DESENVOLVIMENTO NÁUTICO NA PENÍNSULA IBÉRICA ${ }^{1}$
}

\author{
Cristina de Amorim Machado
}

\section{Introdução}

\author{
Ó menina vai ver nesse almanaque como é que \\ isso tudo começou \\ Diz quem é que marcava o tic-tac e a ampulheta \\ do tempo disparou... \\ ChICO BuARQue, Almanaque
}

Neste artigo compartilharei algumas notas sobre alguns textos da literatura científica portuguesa que, articulados com uma farta bibliografia secundária sobre a história da expansão marítima, revelam o papel da tradução e da astrologia no desenvolvimento náutico ibérico dos séculos XIV-XVI, além de ampliar os horizontes de discussão dos próprios conceitos de tradução, astrologia e ciência. Pretende-se, assim, inscrever novos textos e personagens na história geral da tradução, bem como contribuir para uma história da tradução em língua portuguesa, normalmente obscurecida por outras geografias e línguas mais prestigiadas.

Para contextualizar, navegarei um pouco pelas origens da língua portuguesa e de suas primeiras produções. Na sequência, a astrologia e a tradução serão posicionadas no cenário do desenvolvimento náutico na península. Para finalizar, apresentarei os almanaques no contexto da literatura náutica, especificamente Os almanaques portugueses de Madrid (1321), que tenho considerado como a primeira tradução científica $^{2}$ em língua portuguesa.

\section{Os primeiros textos em língua portuguesa}

Em 1279, o rei D. Dinis proclamou a língua portuguesa como idioma oficial e, em 1290, instituiu os Estudos Gerais (Universidade) de Lisboa, depois transferidos para

\footnotetext{
1 Este artigo é decorrência do trabalho "Notas sobre as primeiras traduções científicas em língua portuguesa", apresentado no simpósio A história e a historiografia da tradução do Congresso da ABRAPT realizado em Florianópolis em 2013. Baseio-me aqui no capítulo 7 da minha tese de doutorado, O papel da tradução na transmissão da ciência: o caso do Tetrabiblos de Ptolomeu, que foi também publicada em livro numa versão reduzida (Machado, 2012). No livro, esse conteúdo se encontra no capítulo 6.

${ }^{2}$ Para ver uma discussão sobre o conceito de tradução científica, cf. Machado, 2014, p. 238-244.
} 
MACHADO - Notas sobre as primeiras traduções científicas em língua portuguesa

Coimbra, que tinham como uma de suas tarefas "dar organicidade à língua, defendê-la, difundi-la" (Donato, 2005, p. 116). É a partir do século XIV, já definitivamente separado do galego, e com o eixo Lisboa-Coimbra como centro, que o português moderno, ou português europeu, vai se estabelecer e se inovar, tornando-se o padrão.

A nomenclatura que se costuma usar - galego-português e português europeu faz parte da periodização da língua portuguesa proposta por Paul Teyssier (2004), no seu livro História da língua portuguesa. No entanto há controvérsias. A periodização da língua portuguesa proposta por Evanildo Bechara (1985), na sua tese As fases históricas da língua portuguesa, por exemplo, é outra. Para ele, é possível periodizar o português com base em fatos linguísticos, em vez de históricos, literários ou de qualquer outro tipo. Sua proposta é a seguinte: o português arcaico vai do século XIII ao XIV, o português arcaico médio, do século XV à primeira metade do XVI, o português moderno, da segunda metade do XVI à segunda metade do XVII, e o português contemporâneo, do século XVIII aos dias de hoje. De maneira geral, é possível associar totalmente o galego-português de Teyssier ao português arcaico de Bechara; todavia o português europeu de Teyssier cobriria o português arcaico médio, o português moderno e o português contemporâneo de Bechara.

Independentemente da discussão sobre periodização, o fato é que o meio acadêmico aceita atualmente a Notícia de Torto (1214-1216) e o Testamento de D. Afonso II (1214) como os mais antigos escritos em língua portuguesa (ou galegoportuguesa). Vale lembrar que por muito tempo se acreditou que o Auto de Partilhas (1192) e o Testamento de Elvira Sánchez (1193) eram os documentos mais antigos; no entanto esses primeiros testemunhos foram na verdade escritos em latim nas datas mencionadas e traduzidos para o português no fim do século XIII. Pelos títulos, percebe-se que documentos oficiais e particulares já eram escritos em "linguagem". Acrescentemos a esses pouco emocionantes textos notariais, a poesia lírica peninsular, como os Cancioneiros da Ajuda, da Vaticana e da Biblioteca Nacional de Lisboa, com suas cantigas de amigo, amor e escárnio, e as Cantigas de Santa Maria, de D. Afonso X, o Sábio (1221-1284), rei de Leão e Castela. Essas compilações foram escritas por vários autores galegos, portugueses, leoneses e castelhanos, com base na língua falada na Galícia e no norte de Portugal. Assim como seu avô Afonso X, D. Dinis, rei de Portugal de 1279 a 1325, também foi um trovador, bem como seu filho D. Pedro, conde de Barcelos (1289-1354). Foi ele, D. Pedro, um dos iniciadores da prosa literária 
portuguesa, e lhe são atribuídos o Livro das linhagens e a Crónica geral de Espanha de $1344 .^{3}$

Apesar dessa produção textual independente em português, o intercâmbio com as línguas espanholas continuou por conta de uma história familiar e política comum, da proximidade geográfica, além do compartilhamento de saberes e técnicas. Posteriormente, com a União Ibérica (1580-1640), isso se acentuou. Segundo Teyssier (2004, p. 43), "entre meados do século XV e fins do século XVII o espanhol serviu como segunda língua para todos os portugueses cultos”. Isso é evidente na produção escrita dos anos quinhentistas, tendo em vista que quem escrevia em português, também escrevia em castelhano (como foi o caso do matemático Pedro Nunes e de Camões, só para citar dois exemplos em campos diferentes).

Segundo Sánchez \& Pinilla (2003, p. 217-219), foi um "momento histórico marcado pelo bilinguismo e o predomínio do castelhano", e esse bilinguismo implicou restrição de tradução, havendo pouquíssimas traduções científicas e clássicas até o primeiro terço do século XVII. Há controvérsias sobre isso, provavelmente em função dos critérios quantitativos usados. Não me cabe aqui discutir os critérios de outros pesquisadores, mas vejamos outra opinião, especialmente sobre a corte de Avis, no período de D. Duarte (1433-1438). Sebastião Tavares de Pinho (1993, p. 151) fala num "movimento que podemos considerar como que uma escola de tradução mais ou menos alimentada à volta da Corte”. Ele chega a essa conclusão em função da atividade tradutória de D. Duarte e seu irmão, D. Pedro, que também promoveram traduções, tendo ao seu redor um grupo de tradutores. Além disso, a biblioteca da corte contava com 70 obras traduzidas do latim, e a biblioteca pessoal de D. Duarte, segundo Nascimento (1993, p. 265-287), possuía 84 entradas, sendo 64 obras em vernáculo, a maioria traduzidas. Destas, a propósito, dois volumes catalogados como "livros de astrologia" me chamam a atenção.

No século XVI produziram-se as primeiras gramáticas de português, como a de Fernão de Oliveira (1536) e a de João de Barros (1540), e havia também o "retorno" ao latim, por conta do Humanismo. Sobre isso, A. A. Gonçalves Rodrigues, na introdução do seu A tradução em Portugal, diz o seguinte: “Além do latim, o castelhano serviu durante décadas como veículo obrigatório pelo qual se alimentava a sensibilidade e a

\footnotetext{
${ }^{3}$ Para obter mais informações sobre a Crónica, D. Afonso X, D. Dinis e a conexão entre Portugal e Espanha nesse período, cf. Machado \& Martins, 2010.
} 
cultura do escol português, eclesiástico ou laico." (Rodrigues, 1992, p. 27-28). Ou seja, nessa época, Portugal era um país bilíngue e, nos meios científicos e literários, trilíngue, já que, ao português e castelhano, agregava-se também o latim. Vale lembrar também que é no fim do século XV que se instala a imprensa e começam as Descobertas, e a tradução se beneficia sobremaneira de ambas (Pais, 1997, introdução), bem como a ciência.

\section{Tradução, astrologia e desenvolvimento náutico na península}

Para o que me interessa aqui, além de um certo papel desbravador no que diz respeito à língua e à tradução, também é necessário lembrar o pioneirismo português na expansão marítima dos anos quatrocentistas e quinhentistas, cujo marco inicial se considera, geralmente, como sendo a conquista de Ceuta (1415). A União Ibérica (1580) normalmente é tomada como marco final da expansão. Nesse intervalo de 165 anos, Portugal explorou a costa africana, superou o cabo da Boa Esperança, assinou o Tratado de Tordesilhas e efetivou a expansão para Índia, Brasil, América do Norte, China e Japão, além de fazer a circunavegação. Ao mesmo tempo, eram realizadas viagens terrestres (Teyssier, 1992, p. 13-46).

O desenvolvimento da chamada "navegação astronômica" é igualmente atribuído aos portugueses, muito embora os astros já orientassem a navegação desde tempos imemoriais, como se vê registrado no canto V da Odisseia:

Ele [Ulisses] contemplou as Plêiades, e o Cocheiro que tarde se põe, e a Ursa ou Auriga, como alguns a chamam, cujas rodas giram sem parar onde estão, em face de Orion, e, única entre todas elas, jamais se banha no Oceano. Calipso advertira-o que conservasse a Ursa à sua esquerda, enquanto navegasse pelo mar. (Homero, 1996, p. 63)

Apesar de as práticas náuticas antigas já incluírem técnicas astronômicas, só com a expansão marítima portuguesa é "que as observações astronômicas aplicadas à navegação se desenvolveram realmente" (Mourão, 2000, p. 89), sendo "um dos alicerces donde viriam a desenvolver-se as primeiras tentativas da ciência moderna, que havia de irromper de maneira imparável a partir do início do século imediato" (Albuquerque, 1983, p. 123).

Ademais, desde o início do século XX, com Joaquim Bensaude (1930), tem tido cada vez mais suporte a tese de que uma das forças em jogo nesse desenvolvimento 
MACHADO - Notas sobre as primeiras traduções científicas em língua portuguesa

náutico português foi a presença de astrólogos árabes ${ }^{4}$ e judeus na região. Nesse tempo, os astrólogos eram também astrônomos, já que precisavam dominar a mecânica celeste e a trigonometria esférica, além de manusear tabelas e instrumentos astronômicos - que viriam a se tornar também instrumentos náuticos -, para fazer seus mapas astrológicos. Seguindo essa trilha, é importante destacar que a tecnologia e as ciências de árabes e judeus - em muito tributárias das ciências helenísticas - foram em grande parte disseminadas para o mundo europeu por meio dos movimentos de tradução ocorridos na Idade Média, primeiro em Bagdá, depois em várias cidades da Espanha, como Toledo, Barcelona e Córdoba. ${ }^{5}$

Como já foi dito antes, em Portugal também houve um impulso tradutório, já num período que podemos chamar de renascentista, com o aparecimento de vários textos científicos. Vale lembrar que esses movimentos de tradução, além de reescrita textual, implicavam também a transmissão e modificação de saberes, práticas e técnicas, numa palavra, a transmissão da ciência, ainda que rudimentar. Ciência reescrita, localizada, deslocada no tempo e no espaço, segundo a circunstância que a recebia. A circunstância que ora analiso é a do desenvolvimento da náutica, que, de um punhado de regras, rotinas, observações e experiências vividas e acumuladas ao longo dos tempos pelos navegantes mediterrâneos, vai se transformando, a partir do século $\mathrm{XV}$, em ciência. A expansão para o Atlântico exigiu novas maneiras de navegar, novos procedimentos, técnicas e práticas. Dentre elas, o registro de tudo o que se observava. Segundo Luís de Albuquerque (1983, p. 121-122), essa observação já se aproximava, em alguns casos, do sentido de experimentação dos modernos. Ademais, houve também a especulação produzida por essas observações, e essa atitude indagadora e investigativa talvez seja o principal nexo entre a nova náutica e a ciência moderna.

Levando tudo isso em conta, parto do princípio, já desenvolvido em outro trabalho (Machado, 2012), de que houve uma repercussão de práticas tradutórias e astrológicas na expansão marítima ibérica, uma "herança" que percorreu milhas e línguas, até chegar, na forma de manuais e instrumentos náuticos, aos pilotos portugueses e espanhóis, rumo a "mares nunca dantes navegados". Essa trajetória faz

\footnotetext{
${ }^{4} \mathrm{O}$ termo "árabe" será usado aqui para se referir às pessoas de qualquer religião, nacionalidade ou etnia que falavam, liam ou escreviam em árabe. Trata-se, pois, do mundo de língua árabe. Vale lembrar que, com a expansão do Império Árabe, que também se tornara muçulmano a partir do século VII, a língua árabe e a religião muçulmana difundiram-se conjuntamente.

${ }^{5}$ Para ver uma apresentação desses movimentos de tradução na Idade Média, cf. Machado, 2012.
} 
MACHADO - Notas sobre as primeiras traduções científicas em língua portuguesa

parte da história das ciências e da náutica na Península, e neste artigo estou tratando de algumas questões sobre tradução e astrologia-astronomia, sobretudo porque acredito que essas práticas viabilizaram a sobrevivência, a difusão e o desenvolvimento das ciências antigas.

Voltando a Bensaude (1930), vê-se que, para ele, o conhecimento astronômico português deriva do Almanaque perpétuo do astrólogo salmantino Abraão Zacuto. Bensaude rechaça a tese de Humboldt de que a ciência alemã tenha sido a base da expansão portuguesa, afirmando ser Zacuto seu mentor, principalmente por suas tabelas e simplificação do astrolábio. As tabelas de Zacuto seguem o mesmo modelo das tabelas astronômicas medievais. Segundo Luciano Pereira da Silva (1914, p. 23-4), esse conhecimento vem de uma "longa tradição que, pelos árabes, remonta aos gregos". Além dele, vários astrônomos-astrólogos, nos séculos XVI e XVII, prestaram um serviço extraordinário (Regiomontanus, Kepler, Galileu), porque usavam as tabelas astronômicas para prever acontecimentos humanos, ou seja, para fazer astrologia.

Ainda sobre os antecedentes da expansão marítima, Ronaldo Mourão afirma: "foram os seus conhecimentos [astrologia árabe], divulgados na península ibérica, a base de toda astronomia que permitiu que os portugueses e os espanhóis realizassem as grandes viagens de descoberta" (Mourão, 2000, p. 19). E ainda Guy Beaujouan, logo na primeira página do seu artigo "L'astronomie dans la péninsule ibérique à la fin du Moyen Âge", destaca o papel importante da astrologia como um dos cinco traços característicos da ciência ibérica da baixa idade média (os outros quatro são: impregnação árabe, debilidade das universidades, emprego do vernáculo e lugar de destaque dos judeus). Indo mais além, ele diz: "A astrologia era a meta essencial da atividade dos astrônomos. Negar isso seria atribuir somente às necessidades da astronomia náutica a confecção das tábuas astronômicas, o que não procede. (Beaujouan, 1969, p. 5-6)

Além de Zacuto, Pedro Nunes, João Faras e José Vizinho também podem ser considerados astrônomos-astrólogos e contribuíram para aperfeiçoar a matemática e os instrumentos e procedimentos náuticos. Ademais, João Faras traduziu o De situ orbis de Pompônio Mela, José Vizinho traduziu o Almanaque perpétuo de Zacuto, e Pedro Nunes traduziu parte da Geografia de Ptolomeu, o Tratado da esfera de Sacrobosco, fez autotradução e tem um discurso favorável à tradução como divulgação científica. Todos eles já foram apresentados em outros trabalhos (Machado, 2010; 2012). 
MACHADO - Notas sobre as primeiras traduções científicas em língua portuguesa

Pode-se dizer, portanto, que se aliaram a riqueza e a vitalidade da tradição castelhana à cultura astrológica portuguesa no início dos quatrocentos (Beaujouan, 1969, p. 11). Ainda sobre esses antecedentes, e voltando mais uma vez a Bensaude, ele atribui grande importância aos movimentos tradutórios no medievo e, mais ainda, identifica o expansionismo português com um certo espírito tradicional:

É o espírito de cavalaria da Idade Média, e não a Renascença, que funda a grande época portuguesa com Nuno Álvares; é o espírito religioso que guia o Infante D. Henrique [...]. Para estudar o grande impulso artístico na Itália do século XVI, é necessário ir direto à fonte: os construtores das catedrais da Idade Média. [...] A revolta em matéria religiosa, provocada pela Reforma, teve suas origens na sede de ciência e saber. Essa sede nasceu não na Itália, mas na Península, em plena Idade Média, na grande época das traduções do árabe das obras de filosofia, medicina, astronomia, uma verdadeira febre epidêmica tornou-se intensa na Provença e na Península desde o século XI. (Bensaude, 1930, p. 434-5)

Em relação à transição da prática náutica para uma "ciência náutica", percebe-se que houve uma certa tensão nesse momento inicial. No século $\mathrm{XV}$, poucos pilotos dominavam os elementos teóricos da navegação, tratava-se de uma elite de homens de confiança, depositários de um segredo nacional. A maioria dos pilotos tinha experiência prática e sua grande escola era o mar, como aponta Albuquerque no seu Dúvidas e certezas na história dos descobrimentos portugueses (1990, p. 26):

Não era possível preparar marinheiros com exposições teóricas que lhes haviam de ser completamente inúteis; mas tão-pouco era viável prepará-los praticamente, porque se ignorava de todo as dificuldades que iam enfrentar e vencer. Eles mesmos encontraram na prática das navegações os meios para as resolver, com auxílio dos astrólogos a quem bastava, para isso, usar conhecimentos rudimentares de astronomia.

Como seus resultados eram brilhantes e normalmente sua avaliação e seus julgamentos valiam mais que a de um piloto erudito, opuseram-se à "cientificização" do domínio da navegação, daí o conflito entre marinheiros e eruditos por volta de 1530 . No entanto "o aumento do número de navios e das distâncias percorridas, sobretudo a penetração no hemisfério sul, exigiram a intervenção da ciência”. O favorecimento de Portugal no Tratado de Tordesilhas resulta disso, dessa "superioridade tecnológica" que se manteve reservada aos pilotos lusos ou a serviço da coroa lusitana (Bensaude, 1930, p. 283-4). Sobre essa transição de arte náutica para ciência náutica, apresento, a seguir, o que Luís de Albuquerque diz no seu Ciência e experiência nos descobrimentos portugueses (1983). 
MACHADO - Notas sobre as primeiras traduções científicas em língua portuguesa

No início do período medieval, a navegação era costeira, o que dispensava qualquer orientação magnética ou geográfica, como a determinação de latitudes. Os relatos de outros pilotos, que incluíam as distâncias arredondadas entre alguns portos, foram as primeiras "ferramentas" náuticas. A "agulha de marear”, ou bússola, surgiu no século XIII, talvez um pouco antes, com a intensificação das navegações. Nesse período, os relatos dos pilotos, já chamados então de "portulanos", passaram a incluir também o rumo magnético para ir de um porto a outro e o "estabelecimento do porto", que era a fixação da hora da preamar no dia de lua nova em certo porto, para daí inferir as horas das marés nos dias seguintes. Antes do século $\mathrm{XV}$, surgiram as "cartas de navegar", depois chamadas de "cartas-portulanos", e as "toletas".

Para Albuquerque, essas cartas nada mais eram do que a representação gráfica dos portulanos, o que implicava uma série de problemas geográficos. No entanto a presença das linhas dos rumos magnéticos incrementava sobremaneira essas representações, que se mostravam muito úteis em termos náuticos. Até aqui, além do registro da experiência vivida pelos pilotos, o máximo que se exigia era uma certa técnica para desenhar os mapas e um conhecimento mínimo de geometria. As toletas, por sua vez, já exigiam aparentemente um saber mais refinado. Derivadas de cálculos trigonométricos, elas auxiliavam os pilotos a regressarem ao rumo certo em caso de desvio.

Indo mais adiante, Albuquerque afirma que essa prática no início dos quatrocentos não se tratava de navegação astronômica no sentido que os historiadores da ciência entendem esse termo hoje. Para assim ser denominada, a navegação deve incluir uma observação dos astros feita no mar, com base em alguma medida que a oriente, como a latitude, por exemplo. Apesar de alguns almanaques portugueses dessa época já incluírem a latitude, essa medida não era usada para fins náuticos, e sim astrológicos, como se vê em Os almanaques portugueses de Madrid, apresentados na próxima seção como a provável primeira tradução científica portuguesa. A rotina dos homens do mar só começou a mudar mesmo em meados do século XV, com a expansão das rotas de navegação para o Atlântico e seus novos desafios. Isso acarretou um surto de ciência náutica, com o incremento da cartografia, da mentalidade crítica e das práticas de navegação, incluindo declinação magnética e determinação de latitudes.

Além das técnicas, outras questões se produziram nesse movimento expansionista, que são analisadas por J. S. da Silva Dias no seu Os descobrimentos e a 
MACHADO - Notas sobre as primeiras traduções científicas em língua portuguesa

problemática cultural do século XVI. Logo na introdução ele fala da astrologia: "No próprio campo da astrologia, em que tanto nos esforçámos, não foi mais veloz cá dentro do que lá fora a separação da astrologia natural e da estrologia judiciária" (Dias, 1988, p. 11). Podemos entender aqui "astrologia natural" como astronomia, e "estrologia judiciária" como astrologia. Dias também destaca que o empreendimento das Descobertas foi igualmente obra de portugueses e espanhóis, e que se insere mais no quadro do Renascimento do que do Humanismo, ou seja, não foi uma empreitada de latinistas e acadêmicos, e sim de práticos, pessoas com experiência no mar. Um ponto que ele toca é que, além das Descobertas, outras circunstâncias concorreram para a evolução da cultura e das ciências na Europa (por exemplo, a invenção da imprensa), e isso explicaria, em grande parte, por que essa evolução foi mais rápida além do que aquém dos Pirineus.

No capítulo VII de seu livro, Dias ensaia uma explicação para o fixismo cultural português observado no fim dos seiscentos. Segundo ele, Portugal se manteve afastado das inquietações filosóficas e científicas do resto da Europa porque a expansão gerou contradições na cultura nacional. A censura, a Inquisição e a contra-reforma (com integração violenta do judeu) salvaguardaram perenidades culturais medievais, ou seja, os âmbitos filosófico e cultural são solidários ao teológico. Exemplo disso foi o exílio para a Holanda, em 1640, da família daquele que viria a ser, para muitos, um dos filósofos mais representativos de sua época, Baruch Spinoza (1632-1677).

A modéstia e a carência de autonomia são mencionadas por Dias como "dois pilares fundamentais do edifício cultural português no período quinhentista. A força da sua inércia constituía um obstáculo de peso à exploração, pelo menos à exploração maciça, das Descobertas como motor ou redutor da nossa “forma mentis"” (Dias, 1988, p. 269). Além disso, a influência dos jesuítas também é lembrada por Dias na constituição desse cenário:

A observação e a experimentação não conseguiram impor-se ao comentário dialético de velhos textos e à construção especulativa. [...] A ânsia experimentalista que emanava da empresa ultramarina foi, juntamente com a busca metodológica e a demanda do conhecimento positivo, um dos grandes excluídos da sistematização inaciana. E isso distanciou-nos, alheou-nos mesmo, de um caminho principal do pensamento europeu evoluído (ibid.).

Nessa passagem, apesar de a expressão "pensamento europeu evoluído" ser suspeita, isso não invalida a sua colocação sobre o distanciamento português do projeto 
de modernidade. Além disso, a perda da independência, em 1580, levou Portugal à decadência, a um amargo desengano e ao pessimismo moral: "éramos poucos para assegurar a independência da pátria". Com isso, havia sempre os "imperativos práticos da nação" e um "desvio de seiva criadora para as tarefas da defesa nacional", ou seja, "não sobrava o tempo para a investigação científica ou para a leitura desinteressada" (ibid.).

O período das Descobertas, como visto até aqui, demandou uma especialização e instrumentalização que, além dos aparatos náuticos propriamente ditos, só conhecidos pelos astrônomos-astrólogos, também incluía tabelas e textos astronômico-astrológicos. Grande parte desse material já vinha sendo transmitida na Península Ibérica há alguns séculos, o que implicou a formação de uma literatura especializada, que será brevemente apresentada a seguir.

\section{Os almanaques e a literatura náutica}

Em outro trabalho (Machado, 2012) já argumentei que os textos de astrologia, como os de outras ciências helenísticas, passaram por uma série de traduções (principalmente do grego para o árabe e, depois, do árabe para o latim) até chegarem à forma que conhecemos hoje, totalmente reescritos nas mais diversas línguas. Não vou repetir isso aqui, mas é preciso destacar que, além desses textos helenísticos, cujo percurso já se conhece, havia também, nesse cenário expansionista, a literatura náutica. Segundo Albuquerque (1972, p. 256), "da actividade marinheira dos séculos XV e XVI surgiu uma vasta literatura técnica, que também foi um bom meio de aprendizagem". Distinguem-se, nessa literatura, quatro tipos de obras: guias náuticos, roteiros, diários e livros de marinharia. Dentre eles, os mais antigos - Guia náutico de Munique (1509) e Guia náutico de Évora (1516) - incluem a tradução (para o português) quase integral do Tratado da esfera, de João de Sacrobosco, sobre o qual já falei em outros trabalhos (Machado, 2010; 2012). Para alcançar o objetivo deste artigo, tenho agora que tratar também de um outro tipo de texto - os almanaques -, e é isso que apresentarei a seguir.

Às vezes chamados de repertórios, lunários, efemérides, prognósticos, guias, entre outras denominações, os almanaques (em árabe, al manakh significa calendário) funcionam como um calendário anual, fornecendo informações resumidas sobre vários saberes, orientações práticas para o dia a dia e previsões meteorológicas, de maneira geral com base na astrologia (Lisboa, 2002, p. 11-12). Os almanaques não são incluídos 
MACHADO - Notas sobre as primeiras traduções científicas em língua portuguesa

por Luís de Albuquerque no sistema de literatura náutica, mas, de certo modo, "apetrechavam" a marinharia, como ele mesmo diz na sua publicação de $O s$ almanaques portugueses de Madrid (Albuquerque, 1961, p. 4, 7, 8):

\begin{abstract}
Através dos textos recentemente integrados na História da Cultura Portuguesa, ou em vias de o serem, não é já possível recusar que a astrologia árabe e judaica, nos seus dois aspectos técnico e judiciário, teve entre nós maior aceitação do que se supunha, e muito antes de ter sido reclamado o seu concurso para o apetrechamento da marinharia. [...] Entretanto, para além das influências directas exercidas por alguns escritos medievais de astrologia, comprovadas pelos textos que foram até agora encontrados, não seria muito arrojado fazer a previsão de que ensinamentos de não menor alcance podiam ter sido indirectamente aproveitados. [...] Reconheça-se que, não sendo fácil pressentir estas influências indirectas, apenas adivinhadas na leitura dos documentos [...] será na esteira da tradição da astrologia judáica que terão essencialmente de prosseguir os investigadores.
\end{abstract}

Num breve resumo desse tipo de literatura, Albuquerque cita quatro manuscritos do século XV que ilustram a tese de que "foi àquele grupo [de astrólogos] que se recorreu quando se tornou urgente enriquecer a náutica com uma técnica menos falível do que a até então adoptada" (ibid., p. 7). Cada um desses manuscritos mereceria um estudo detalhado, até porque envolvem questões tradutórias, mas não me desviarei a esse ponto do rumo traçado, ficam aqui a sugestão e o registro de seus nomes e localizações: 1) Tabulae astronomicae, Biblioteca da Ajuda; 2) De judicis astrorum de Aben Ragel, Museu Britânico; 3) Livro de mágica de João Gil, Museu Britânico; e 4) Tratado da esfera de Sacrobosco, Biblioteca Nacional de Lisboa (BNP).

É chegada a hora de falar um pouco de um texto específico, Os almanaques, pois se trata, em grande parte, de uma tradução de um almanaque árabe, ou seja, a primeira tradução científica para a língua portuguesa de que tenho notícia, datada provavelmente de 1321. Na esteira da tradição astrológica dos quatrocentos e quinhentos é que se inserem Os almanaques portugueses de Madrid, assim denominados por se encontrarem no códice 3349 da Biblioteca Nacional de Madrid. Segundo Albuquerque (ibid., p. 37), as notas e observações à margem dos manuscritos indicam o grau de preparo dos autores da versão portuguesa ou dos astrólogos que a usaram. Além de dados de interesse exclusivamente astrológico (ver Anexo 1), Albuquerque também destaca o seu aporte para a astronomia, a geografia, o calendário e, evidentemente, para a história das ciências: os almanaques portugueses mostram "o nível técnico alcançado por astrólogos portugueses, ou radicados em Portugal, em época 
MACHADO - Notas sobre as primeiras traduções científicas em língua portuguesa

anterior aos decisivos progressos experimentados pela marinharia dos Descobrimentos" (Albuquerque,1961, p. 41). Dando um passo adiante, ele ainda complementa dizendo que essa é: "uma prova irrefutável de que em Portugal já no século XIV viviam homens com capacidade para empreenderem com sucesso, caso isso lhes fosse exigido, a adaptação de algumas regras astronómicas às condições da sua utilização náutica" (ibid.).

Detalhando um pouco mais, trata-se de uma tradução portuguesa feita a partir de uma tradução latina de um almanaque árabe de 1307, que se baseia no texto e nas tábuas de Azarquiel (século XI). A maior parte do texto é de 1321, sendo alguns manuscritos de 1339. O material foi preparado em vários lugares (pelo menos Lisboa, Coimbra e Santarém), por astrólogos diferentes, que mantiveram quase todas as tabelas em latim. Os almanaques dividem-se em duas partes. A primeira é um conjunto heterogêneo de fragmentos de quatro manuscritos que totalizam 21 páginas. Pelo menos um deles foi produzido em Coimbra, como se vê no Anexo 2. É provavelmente parte de um texto mais extenso, talvez de caráter didático (a universidade se encontrava nessa cidade de 1308 a 1338 e tinha curso de medicina que, na época, era estudada junto com a matemática e a astrologia), e contém elementos referentes ao calendário, e elementos de interesse astronômico, astrológico e geográfico. A segunda parte é um conjunto mais homogêneo de manuscritos e contém 83 páginas. Trata-se de um almanaque perdurável, ou seja, contém "efemérides perpétuas", que podem ser usadas ciclicamente sem necessidade de grandes correções. Como se vê nos Anexos 3 e 4, os textos são bilíngues e as tabelas não foram traduzidas.

Quando se fala em almanaques, não se pode deixar de voltar a mencionar o Almanaque perpétuo (Zacuto, 1986), publicado em Portugal em 1496. Além de orientação fundamental aos navegadores, esse almanaque pode ser considerado emblemático desse gênero de literatura, como sugere o título do seguinte catálogo da BNP: Os sucessores de Zacuto: o almanaque na Biblioteca Nacional do século XV ao XXI (Galvão, 2002). De 1496 a 1966, esse catálogo identificou 861 almanaques na BNP. No século XVII, essa literatura se popularizou deveras, sobretudo em Lisboa, que, "além de ser uma das cidades mais populosas da Europa naquela época, era o principal centro de produção, impressão e consumo dos prognósticos e lunários” (Carolino, 2002, p. 45). 
MACHADO - Notas sobre as primeiras traduções científicas em língua portuguesa

Essa popularização dos almanaques cruzou o Atlântico e ainda se pode ver no fim do século XIX, imortalizada por Machado de Assis no conto "Como se inventaram os almanaques" de 1890, cujas primeiras e últimas palavras são as seguintes: "Some-te bibliógrafo! Não tenho nada contigo. Nem contigo, curioso de histórias poentas. [...] Vou dizer como se inventaram os almanaques. [...] E hão de chover almanaques. O Tempo os imprime, Esperança os brocha; é toda a oficina da vida."; e igualmente no livro Almanaques de Eça de Queirós (2002, p. 37), publicado em 1896: "Só com o almanaque, sempre presente e sempre ensinante, pode existir regularidade e periodicidade na vida de uma Sociedade [...]. Por isso cada povo que se organiza, e se prepara para a História, imediatamente redige o seu almanaque [...]." Apesar de os almanaques contemporâneos serem bem diferentes dos medievais e renascentistas, em ambos os trechos ainda se vê o que talvez seja a sua principal característica: a preocupação com a qualidade do tempo, questão essa tipicamente astrológica.

Para finalizar, vale lembrar que, ao contrário do Almanaque de Zacuto, os Almanaques portugueses de Madrid não têm relação direta com a expansão marítima, mas indicam a presença de astrólogos em Portugal no século XIV, ou seja, especialistas em medições astronômicas capazes de instrumentalizar a navegação. Isso é importante em termos historiográficos, tendo em vista a agenda portuguesa de, por meio dessas novas fontes, refutar a tese de Humboldt de que teria sido a ciência alemã a responsável pelo desenvolvimento náutico português no século XV.

\section{Considerações finais}

Este momento poderia ser usado para, mais uma vez, lembrar o papel coadjuvante que, por vários motivos, normalmente cabe à tradução em língua portuguesa e à astrologia respectivamente nos estudos da tradução e na história das ciências, e também para falar da circulação do conhecimento e das próprias noções de ciência e tradução. No entanto, como isso já foi explorado em outros trabalhos (Machado \& Martins, 2010; Machado, 2012) e o espaço já está acabando, finalizarei com mais algumas palavras sobre Os almanaques portugueses de Madrid, que, no momento, considero como a primeira tradução científica em língua portuguesa.

A publicação de Os almanaques nos anos 1960 faz parte de um movimento da historiografia portuguesa do século XX de desencavar e divulgar novas fontes para refazer a narrativa do desenvolvimento náutico do século XV de maneira a se afastar da 
solução alemã. Com isso, entraram em cena novos atores, como os astrólogos-tradutores locais, que seriam capazes de instrumentalizar o desenvolvimento da navegação astronômica. Em decorrência desse movimento, não só a historiografia da ciência náutica portuguesa toma novos rumos, trazendo à tona a astrologia, como também a historiografia da tradução se enriquece com a inscrição de novos personagens, textos e geografias.

\section{Referências}

ALBUQUERQUE, L. Os almanaques portugueses de Madrid, separata da Revista da Universidade de Coimbra, 21, Agrupamento de Estudos de Cartografia Antiga / Junta de Investigações do Ultramar, 1961.

Curso de história da náutica. Coimbra: Livraria Almedina, 1972.

. Ciência e experiência nos descobrimentos portugueses. Lisboa: Instituto de Cultura e Língua Portuguesa/Ministério da Educação, 1983.

Dúvidas e certezas na história dos descobrimentos portugueses. Lisboa: Veja, 1990.

BEAUjOUAN, G. L'Astronomie dans la Peninsule Ibérique à la fin du Moyen Âge. Separata de Revista da Universidade de Coimbra, vol. 24, 1969.

BECHARA, E. As fases históricas da língua portuguesa. Niterói: UFF, 1985 (inédito).

BENSAUDE, J. Lacunes et surprises de l'histoire des decouvertes maritimes, $1^{\text {a }}$. Parte. Coimbra: Imprensa da Universidade, 1930.

CAROLINO, L. A escrita celeste. Rio de Janeiro: Access, 2002.

DIAS, J. Os descobrimentos e a problemática cultural do século XVI. Lisboa: Editorial Presença, 1988.

DONATO, H. Onde participamos da aventura: a língua portuguesa. In: STÖRIG, H. A aventura das línguas: uma história dos idiomas do mundo. Tradução de Glória Paschoal de Camargo. São Paulo: Editora Melhoramentos, 2005.

GALVÃO, R. (Coord.). Os sucessores de Zacuto: o almanaque na Biblioteca Nacional do século XV ao XXI. Lisboa: BNP, 2002.

HOMERO. Odisséia. Tradução de Fernando C. de Araújo Gomes. RJ: Ediouro, 1996.

QUEIRÓS, E. Almanaques. Lisboa: Biblioteca Nacional, 2002. 
MACHADO - Notas sobre as primeiras traduções científicas em língua portuguesa

LISBOA, J. Almanaques. In: GALVÃO, R. (Coord.). Os sucessores de Zacuto: o almanaque na Biblioteca Nacional do século XV ao XXI. Lisboa: BNP, 2002.

MACHADO, C. As vozes ruidosas das traduções modernas do Tetrabiblos de Ptolomeu: um relato de experiência de tradução científica. In: ESTEVES, L.; VERAS, V. (Orgs.). Vozes da tradução: éticas do traduzir. São Paulo: Humanitas, 2014.

O papel da tradução na transmissão da ciência: o caso do Tetrabiblos de Ptolomeu. RJ: Editora Mauad X, 2012.

A tradução de textos científicos no período da expansão marítima, uma história em construção. Tradução em Revista (Online), v. 8, p. 1-19, jan./jun. 2010.

MACHADO, C.; MARTINS, M. Revendo o cânone hegemônico da história das teorias de tradução: o pioneirismo de D. Duarte, rei de Portugal. Cadernos de Tradução, no. XXV, p. 9-28, 2010.

MACHADO DE ASSIS. Como se inventaram os almanaques. Almanaques das fluminenses (Contos avulsos), 1890. Disponível em: <machado.mec.gov.br>. Acesso em 22 de dezembro de 2014.

MOURÃO, R. A astronomia na época dos descobrimentos: a importância dos árabes e judeus nos descobrimentos. RJ: Lacerda Ed., 2000.

NASCIMENTO, A. As livrarias dos príncipes de Avis. Biblos, v. LXIX, 1993, p. $265-$ 287.

PAIS, C. Teoria diacrónica da tradução portuguesa: antologia (séc. XV-XX). Lisboa: Universidade Aberta, 1997.

PINHO, S. D. Pedro e a "escola" de tradutores da corte de Avis. Biblos, v. LXIX, 1993, p. $129-153$.

RODRIGUES, A. A tradução em Portugal. Lisboa: Imprensa Nacional - Casa da Moeda, 1992.

SÁNCHEZ, M.; PINILLA, J. El humanismo renacentista y la traducción en Portugal en los siglos XVI y XVII. In: PINILLA, J.; VALENCIA, M. (Eds.). Seis estudios sobre la traducción en los siglos XVI y XVII. Granada: Editorial Comares, 2003

SILVA, L. O livro do Sr. J. Bensaude L'astronomie nautique au Portugal à l'époque des grandes découvertes. Coimbra: Imprensa da Universidade, 1914. 
MACHADO - Notas sobre as primeiras traduções científicas em língua portuguesa

TEYSSIER, P. Cem anos gloriosos. In: CHANDEIGNE, M. (Org.). Lisboa ultramarina - 1415-1580: a invenção do mundo pelos navegadores portugueses. Tradução de Lucy Magalhães. RJ: Jorge Zahar Editor, 1992.

. História da língua portuguesa. Tradução de Celso Cunha. SP: Martins Fontes, 2004.

ZACUTO, A. Almanach Perpetuum. Introdução de Luís de Albuquerque. Lisboa: Imprensa Nacional-Casa da Moeda, 1986. 
MACHADO - Notas sobre as primeiras traduções científicas em língua portuguesa

\section{Anexo 1}

A meytade solar he do começo de leo, ata cima de capricornio. e a outra mey / dade do zodiaco he lu[n]ar; As planetas an .5. dignidades pelos signos. / E cada huma desas dignidades, ha certas dignidades 9 pri[meira]mente an If Casa. / शExaltaçon I triplicidade. If termho If E face. Outrosy a casa ha .5. dignida/des. If Exaltaçon 4. If a triplicidade .3. If o termho .2. II a façe. huma. //

Signos mascolinos som os do fogo. e do aar. e som fortunados. femininos son os/da agoa e da terra e som infortunados. //

Os signos dereitos som da / prima parte de cancer/ ata cima de / Sagitario. /I
Os signos tortos som da prima / parte de capricornio ata / cima de gemini. //

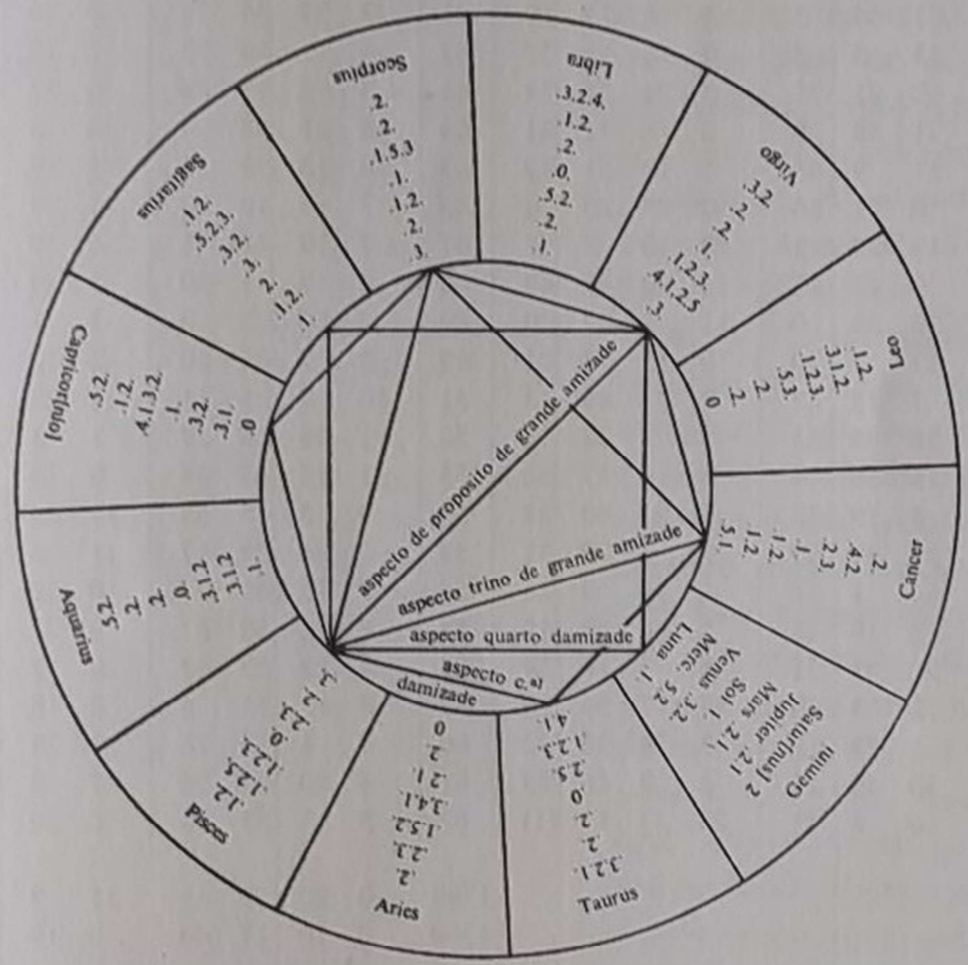

Nota que non muyto asinadamente Saturno anda en .30. dias huum grao. e som .2. meu / dos no dia. Item Jupiter no mes .2. graos. e meudo. Item mars en .2. dias huum, grao. Item / sol. huum. grao. Item luna .13. graos 10. meudos. 35. segundos. E todo esto he certa da verdade. / O sol anda .59 . meudos .8 . segundos. 
MACHADO - Notas sobre as primeiras traduções científicas em língua portuguesa

Exemplo de página com interesse exclusivamente astrológico.

Fonte: Os almanaques portugueses de Madrid (Albuquerque, 1961, p. 65). 
Anexo 2

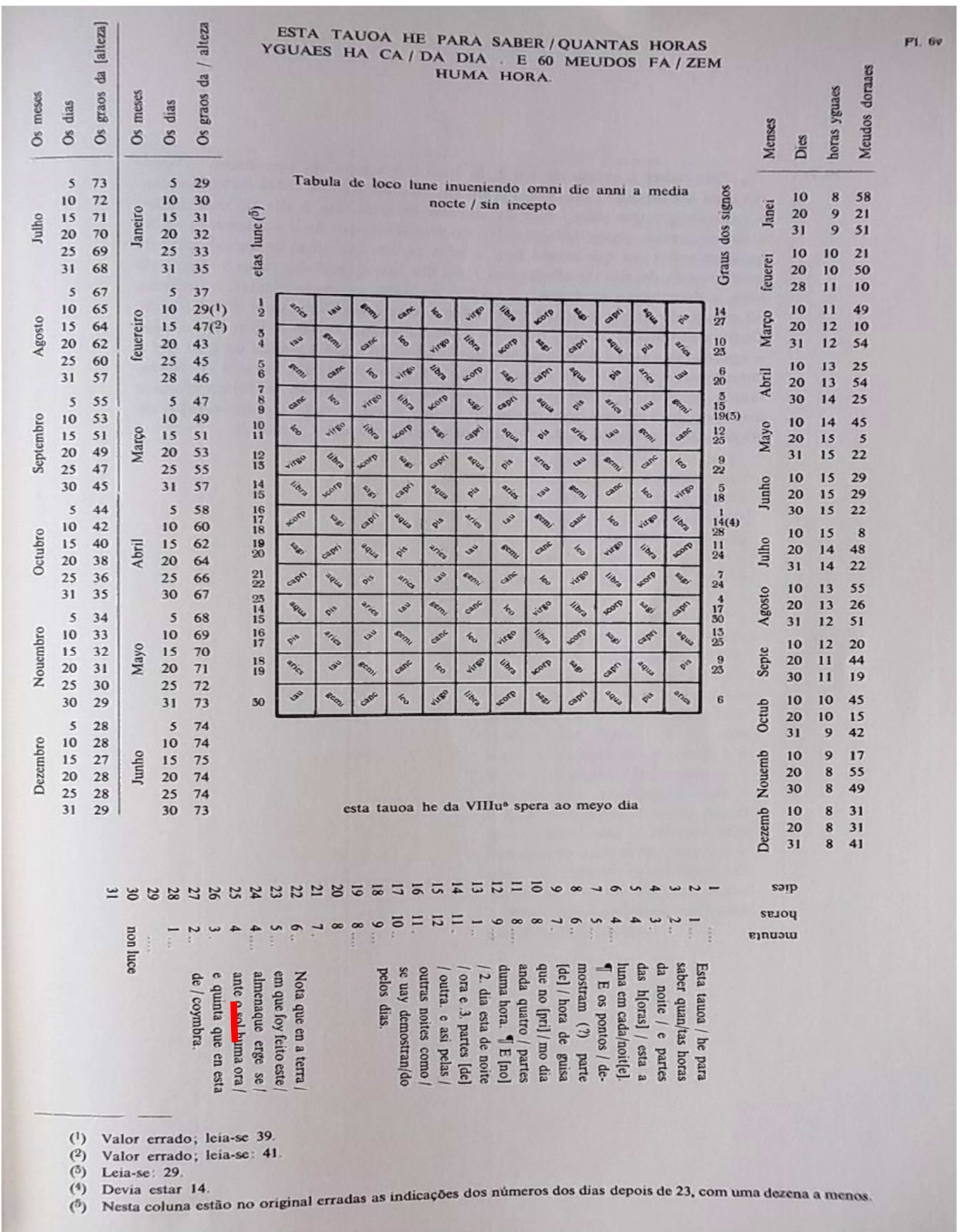

Exemplo de página com interesses astronômico, astrológico, geográfico e de calendário.

Referência a Coimbra sublinhada em vermelho na parte inferior.

Fonte: Os almanaques portugueses de Madrid (Albuquerque, 1961, p. 55). 
MACHADO - Notas sobre as primeiras traduções científicas em língua portuguesa

\title{
Anexo 3
}

F1. $13 \mathrm{r}$

\author{
[ALMANAQUE PERDURÁVEL]
}

[CÂNONES]

Em nome de noso senhor ihesu chrispto aqui se come/ça almanac per. durauel para achar os uerdadeiros / logares das pranetas en nos signos. If Tira dos anos de / ihu $x^{0} .1306$. E com o que ficar entra na tauoa de cada una / praneta no ano e mes e dia e acharas o seu uerdadeiro lo/go se deus quiser. I do Sol asi procede parte aquelo que ficar de .1306. / anos por quatro. e se ficar huum sera o sol na primeira tauoa. e si / ficarem .2. sera o sol na segunda tauoa. e si ficarem tres sera / o sol na tercera tauoa. e se ficarem quatro sera o sol na quarta ta/uoa. TE quando fores na fin da quarta tauoa outra uegada / torna aa primeira tauoa e asi sempre procede da primeira a $.2 .^{\mathrm{a}} / \mathrm{e}$ da $\cdot 2 .^{\mathrm{a}}$ a $\cdot 3 .^{\mathrm{a}} \mathrm{e}$ da $\cdot 3 .^{\mathrm{a}}$ a $\cdot 4 .^{\mathrm{a}} \mathrm{e}$ asi non se consome nem mengua / mais durara sempre aquele curso quanto deus quiser. IE si qui / seres saber em qual grao do signo sera o sol sabe quantos di / as som do mes e entra com aquel dia em na linha primeira hu / see scrito dies do mes. e aquelo que achares em direito do mes / filha signos e graos e meudos e

In nomini nostri Iesu christi. Incipit almanach perpetuum ad inveniendum vera loca planetarum in signis. Substrahe igitur ab annis Christi 1306 et cum residuo intra tabulas cuiuslibet 5 planetarum in anno, mense et die et invenies suum verum locum, si Deus voluerit.

De sol sic procede, divide residuum quod remanet ab annis Christi substractis 1306 per 4, et si remaneat 1 , sol erit in prima tabula. Et si remanent 2 , sol erit in secunda. Et si remanent 3, sol erit in tertia. Et si 4, erit sol in quarta. Et quando erit sol in fine 4 tabule, interato revertere ad primam tabulam, et sic semper procedid a prima ad secundam et a secunda ad tertiam et a tertia ad quartam, et sic non complebitur, vero durabit semper cursus ille quamdiu Deus voluerit.

DE MOTU SOLIS PRIMO. Si ergo vis scire in quo signo sit sol et in quo gradu illis signi, scito quota est dies illius mensis in quo tu es, et intra cum illo die in linea prims ubi scribitur de super dies, et respice dies mensis, et quod videris scriptum mensis in capite tabule, et quod invenies in directo de gradibus, minutis et secundis. id est quod transivi sol in meridie de illo signo quod est cum illo mense.

Exemplo de página da segunda parte de Os almanaques com seu texto bilíngue. Fonte: Os almanaques portugueses de Madrid (Albuquerque, 1961, p. 68). 


\section{Anexo 4}

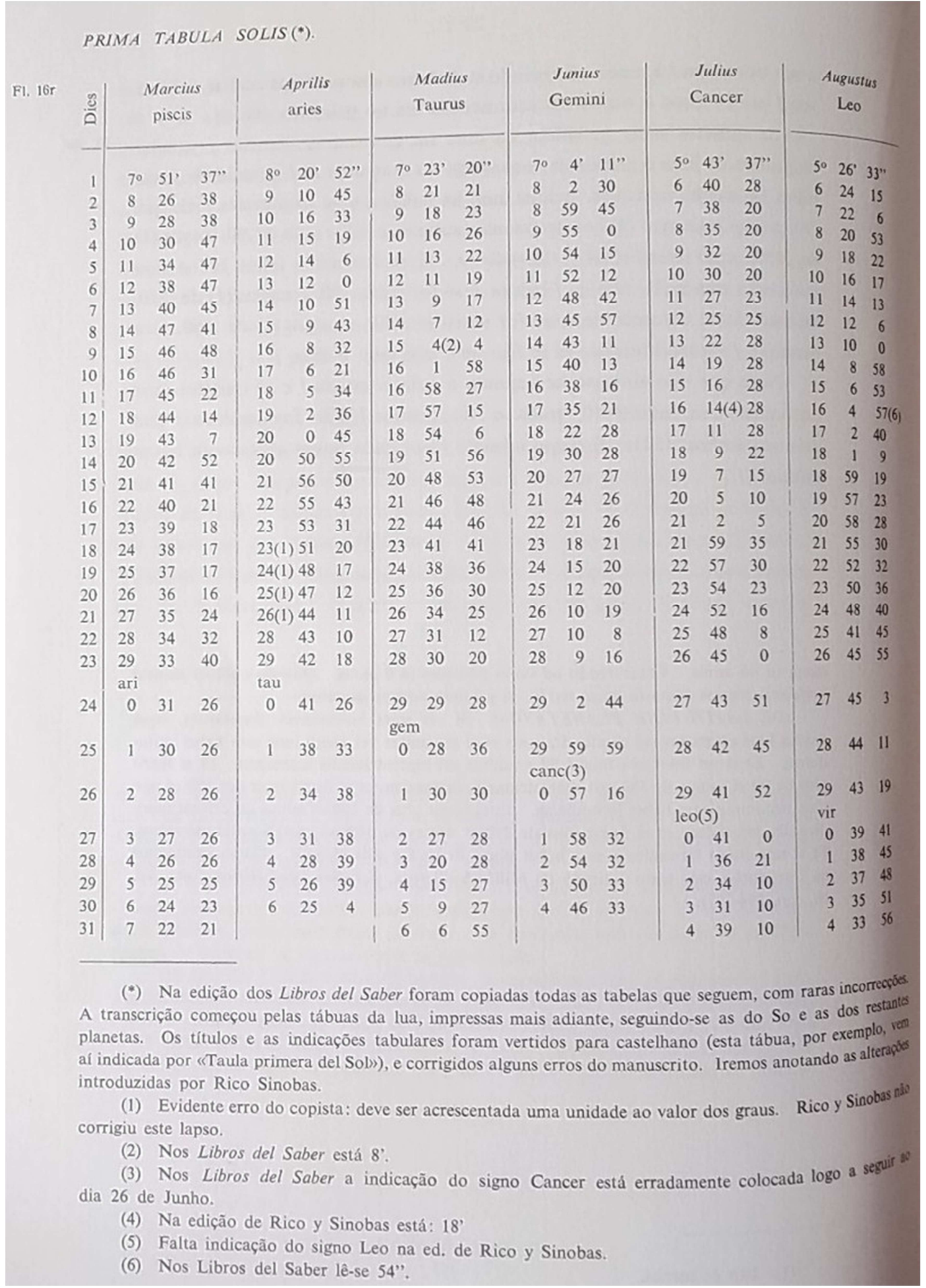

Exemplo de página da segunda parte de Os almanaques com suas tabelas em latim. Fonte: Os almanaques portugueses de Madrid (Albuquerque, 1961, p. 74). 